\section{ECCOMAS}

Proceedia
COMPDYN 2021

$8^{\text {th }}$ ECCOMAS Thematic Conference on Computational Methods in Structural Dynamics and Earthquake Engineering M. Papadrakakis, M. Fragiadakis (eds.) Streamed from Athens, Greece, 28 - 30 June 2021

\title{
MODELLING OF THE OUT-OF-PLANE BEHAVIOUR OF UNREINFORCED MASONRY PANELS USING THE DISCRETE MACRO-ELEMENT METHOD (DMEM)
}

\author{
Valeria Cusmano ${ }^{1}$, Bartolomeo Pantò ${ }^{2}$, Ivo Caliò ${ }^{1}$ and Paulo B. Lourenço ${ }^{3}$ \\ ${ }^{1}$ Department of Civil Engineering and Architecture (DICAR), University of Catania \\ Piazza Università 2, 95131 Catania, Italy \\ e-mail: valeria.cusmano@phd.unict.it, ivo.calio@unict.it \\ ${ }^{2}$ Faculty of Engineering, Department of Civil and Environmental Engineering, Imperial College \\ London, UK \\ e-mail: b.panto@imperial.ac.uk \\ ${ }^{3}$ Institute for sustainability and Innovation in Structural Engineering (ISISE), University of Minho \\ Campus Azurém, 4000-058 Guimares, Portugal \\ e-mail: pbl@,civil.uminho.pt
}

\begin{abstract}
Existing unreinforced masonry (URM) buildings, including historical and monumental structures, represent an important architectural and cultural heritage for several countries worldwide. The response of URM, subjected to earthquake excitations, is strongly governed by the out-of-plane (OOP) response of masonry walls, which can lead to local failure mechanisms, even at low levels of seismic loading. The OOP failure conditions are mainly controlled by the geometry of the structure and the masonry quality. Different strategies are used for modelling the OOP response of URM structures including limit analysis and nonlinear FEM. A further recently proposed strategy is based on the discrete macro-element method (DMEM) which allows the simulation of the in-plane and the OOP response of masonry walls with a reduced computational cost compared to the other numerical strategies. In this paper, the DMEM is applied to simulate a masonry wall rocking experimental campaign for which other numerical strategies have already been applied. The dissipation effects, related to the rocking motion and the repetitive impacts, are taken into account according to an equivalent viscous damping approach. Furthermore, the role of masonry deformability is investigated by comparing the results obtained by the DMEM model, for different value of masonry elastic modulus, with those obtained by typical rigid-block based models. The results clearly demonstrate that the DMEM can be efficiently adopted to accurately predict the dynamic response of monumental structures.
\end{abstract}

Keywords: URM structure, OOP failure mechanism, Modelling strategies, DMEM approach, Rigid-block models, FEM analysis. 


\section{INTRODUCTION}

The existing buildings stock in several seismic area world around includes historical and monumental unreinforced masonry buildings (URM) which possess, in some cases, an important architectural and cultural value. The dynamic response of URM subjected to earthquake excitations is governed by the in-plane (IP) and out-of-plane (OOP) response of masonry walls. When the connections between vertical and horizontal structural elements do not guarantee a box-type behavior, the OOP failure mechanisms are the main source of seismic vulnerability of the building and the failure conditions are mainly controlled by the geometry and gravity loads directly applied to the wall. Due to the low tensile strength, cylindrical hinges tend to separate macro-portion of masonry leading to relative rotations between the different parts. If the number of hinges is such that a kinematic mechanism is allowed the corresponding equilibrium limit condition can be evaluated and a limit value of load multiplier leading to the incipient collapse condition can be determined. Due to the negligible tensile strength of masonry and the slenderness that generally characterise masonry walls, masonry walls can lose the equilibrium and overturn even under low values of seismic loadings. However, damage observation after strong earthquakes have proved that dynamic equilibrium can take place even after the rocking mechanism has been activated [1].

The simplified macro-block limit analysis approach is commonly adopted to assess the rocking behavior of masonry walls, according to the original Heyman's hypotheses [2]: notension material, rigid behavior in compression and absence of sliding. Consistently with these assumptions, a number of selected potential local mechanisms are selected whose ultimate loadmultipliers correspond to upper-bound prediction of the effective load-multiplier, according to the limit analysis static theorem. Hence the lower load-multiplier represents the best prediction of the actual collapse mechanism within the investigated ones.

Upon the results of the limit analysis, the rocking capacity is evaluated by following the force-based or displacement-based approaches [3]. The force-based approach, consisting in comparing the load multiplier to the attendend in-situ PGA, represents the easiest tool to assess the seismic capacity of rocking blocks [4]. The displacement-based approach aims at comparing the displacement capacity of the assumed OOP mechanism with the corresponding displacement demand evaluated on an equivalent bi-linear or tri-linear single degree of freedom system [5]. Another simplified analysis method to assess the OOP response of masonry walls is based upon the hypothesis of tilting rigid block [6] according to which non-linear dynamic analyses are performed on a rigid block scheme assumed representative of the rocking behavior of the masonry wall. The dissipations sources involved in the OOP behavior of the wall are considered by means of a coefficient of restitution ruling the velocity of the rocking system after each impact. An extensive review on rigid block dynamics, when applied to URM structures, can be found in [7].

The main sources of approximation of limit analysis and rigid block models are related to the fact that they totally neglect the effects of masonry deformability and do not properly take into account the interaction between the portion of structure subjected to the overturning motion and the remaining part of the structure that is also subjected to the earthquake loadings and represents the source of loading and the constraint at the same time.

More recently, refined advanced discrete models have been applied to assess OOP rocking mechanisms such as the Distinct Element Methods (DEM) according to which masonry units are explicitly modelled by rigid irregular blocks while joints are modelled as a contact unilateral-friction links [8]. It is worth noting that these methods, difficult to calibrate, are quite computational expensive in the case of large structures and for these reasons although promising are currently limited to academic researches. 
An alternative strategy of analysis to assess the OOP rocking mechanisms [CompDyn2017] is based on the discrete macro-element method (DMEM) which allows the simulation of the inplane and the OOP response of masonry walls [Pantò et al 2017]. This innovative method has been firstly proposed and validated in the non-linear static field ( [9] [10]), and more recently has been extended in dynamic field and validated throught the comparison with experimental tests and refined FE simulation [11], [12]. According to DMEM, masonry walls are discretized as a mesh of shear deformable spatial macro-elements interacting through zero-thickness interfaces whose discretization follows a straightforward fiber calibration strategy. The single macro-element has a shear deformability governed by a single degree of freedom. The capability of the proposed DMEM to account for the IP and OOP behavior of masonry structure has been already numerical and experimental investigated [13], [14].

In this paper, the DMEM methods is applied to simulate the experimental response of masonry walls obtained by free-vibration and shake table tests already presented in the literature. Some parametric analyses are also performed to evaluate the influence of energy dissipation and the masonry deformability, comparing the results obtained by the DMEM model to the closed form solution of the classical rocking theory developed by Housner [6].

\section{ANALISIS METHODOLOGY AND OBJECTIVES}

In this paper the rocking behavior of isolated walls exhibiting a cantilever mechanism, parapet wall (PW), or a simple supported wall (SSW) mechanism, is numerically investigated by using the DMEM approach and the classical rocking theory developed by Housner in 1963 [6]. The static schemes of the two considered mechanisms are reported in Figure 1. The main research goal of the present study is to identify and investigate critical issues related to the use of the DMEM model to describe the rocking motion of masonry walls. To reach this objective, the paper aim at:

a) validating an equivalent viscous damping model for the DMEM, consistent to the contact-damping of the rigid model and experimental observations.

b) estimating the effects on the rocking response of the masonry deformability, neglected in all the rigid-block-based approaches.

A brief description of the two methodologies of analysis is reported in the following subsection showing the main hypotheses according to which they are based on and highlighting their differences.

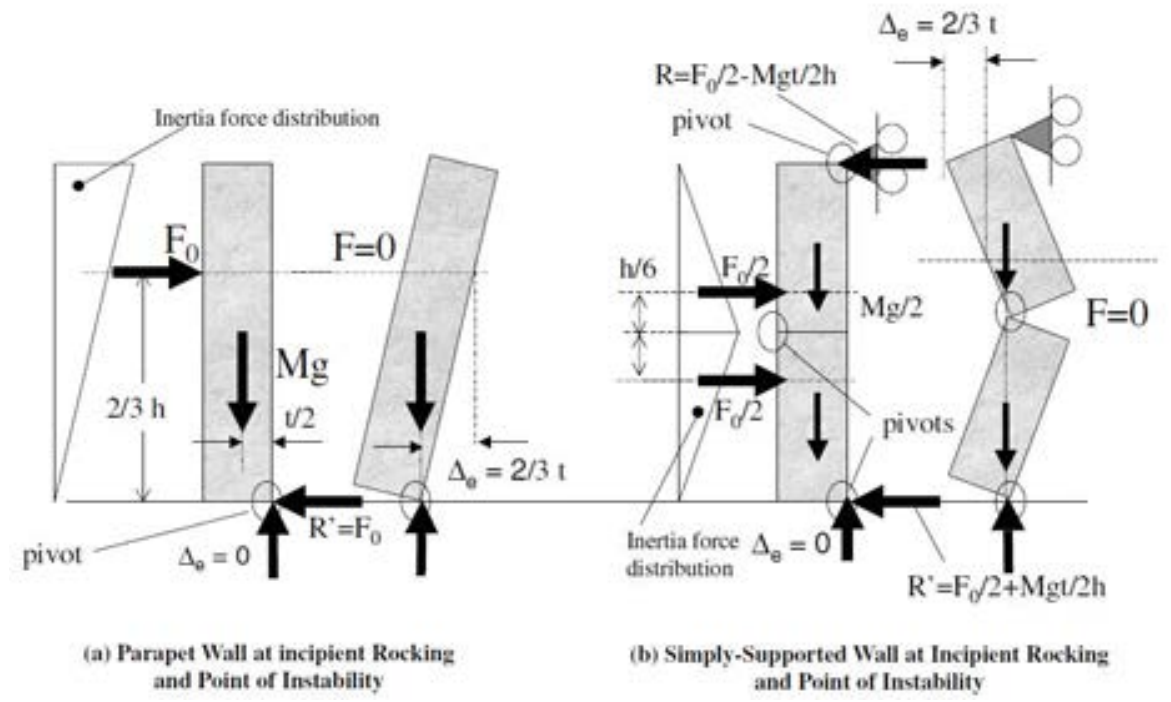

Figure 1: Rocking motion of isolated wall exibiting a cantilever mechnaism (a) and a simply supported mechanism (b) (from Doherty et al. 2002). 


\subsection{Classical Theoretical Model of Housner and the main Geometric Parameters influencing rocking}

The dynamic behavior of a single rigid rectangular block, $2 h$ height and $2 b$ width, standing on a rigid base, with the assumption that friction between the block and the base is high enough to prevent sliding and neglecting bouncing, was first described by Housner in [6], hereinafter referred as the classical theory. When the rocking is activated, the rigid block can pivot on one of the two base vertexes. The main geometric features influencing the rocking response are the slenderness ratio $\alpha=\tan ^{-1}(b / h)$ and the radius vector $R$ connecting the pivot point to the center of mass of the block. A relevant finding of the classical theory is that, between two rigid rectangular blocks of the same slenderness, the block with the higher radius vector is more stable [15]. The equation governing the rocking motion under horizontal, $\ddot{u}_{g}(t)$, and vertical, $\ddot{v}_{g}(t)$, ground acceleration is reported in (1) where the rotation $\theta$ is the rotation angle of the block, assumed as the Lagrangian parameter, $I_{0}$ the moment of inertia of the block about an axis perpendicular to the plane of the wall and passing through its barycenter and $g$ is the gravity acceleration.

$$
\begin{gathered}
\left(m R^{2}+I_{0}\right) \ddot{\theta}+m(h \cdot \cos (\theta)+\operatorname{sgn}(\theta) b \cdot \sin (\theta)) \ddot{u}_{g}+m(\operatorname{sgn}(\theta) b \cdot \\
\cos (\theta)-h \cdot \sin (\theta)\left(g+\ddot{v}_{g}\right)=0
\end{gathered}
$$

The rocking motion of the block $\theta(t)$, can be evaluated by integrating equation (1), within each time interval between two consecutive impacts, considering as initial conditions $\theta\left(t_{i}\right)=$ $0 ; \dot{\theta}\left(t_{i}\right)=\dot{\theta}_{i}$, where $t_{i}$ is the time of the last impact and $\dot{\theta}_{i}$ the rotational velocity of the block after the impact. Considering a free-vibration motion of the block with maximum amplitude $\theta_{0}$, the periods of oscillation of the block (under the assumptions of parapet wall, Figure 1a, and simply supported wall, Figure $1 \mathrm{~b}$ ) are given by:

$$
\begin{gathered}
T_{P W}=\frac{4}{p} \cosh ^{-1}\left(\frac{1}{1-\frac{\theta_{0}}{\alpha}}\right) \\
T_{S S P}=1-2 \sin ^{2}\left(\alpha_{1}\right)
\end{gathered}
$$

Where $p=\sqrt{3 g / 4 R}$ is a frequency parameter of the block referring to the pendulum frequency of the block assumed hanging from its pivot point and $\alpha_{1}$ is the slenderness ratio of simple supported wall. Observing Eqs. (2) and (3), it is worth mentioning that the natural periods of the rigid body motion depend on the rocking amplitude in addition of the geometry of the system.

Several studies have been conducted to investigate the response of a rocking rigid block, subjected to a free-vibration motion ( [6], [16], [17]), harmonic oscillations ( [17], [18]) and earthquake loadings ( [19], [15]). One of the main purpose of these studies was the representation of the energy dissipated during the rocking motion.

According to the classic theory, the dissipation is only concentrated at the impacts, when the rotation is switched from one base vertex to the another. It is generally assumed that the impact induces an instantaneous reduction of the velocity controlled by the introduction of a restitution coefficient $(e)$ ranging from 0 to 1 . A value of $e=0$ corresponds to a totally inelastic impact, while $e=1$ indicates a perfectly elastic impact. By imposing the conservation of the angular moment about the centre of rotation, just before and after each impact, the classical 
theory provides analytical expressions of the restitution coefficient for parapet walls, $e_{P W}$ in Eq. (4), and simple supported walls, $e_{S S W}$ in Eq. (5).

$$
\begin{gathered}
e_{P W}=1-\frac{3}{2} \sin ^{2} \alpha \\
e_{S S W}=1-2 \sin ^{2} \alpha_{1}
\end{gathered}
$$

Some experimental observations showed different values of the restitution coefficient than those predicted by the classic theory [20] suggesting that continuum energy dissipations due to flexural masonry deformation and plastic deformations at the rocking interfaces contribute significantly to the energy dissipation process. In a recent work, Graziotti et Al. [21] found values of the coefficient of restitution coefficient ranging from 0.84 to 0.91 .

In view of to this observations, continuous viscous damping models alternative to the impact dissipation have been adopted, with constant or variable damping ratios, also considering the ease mathematical formulation and software implementation of the viscous damping model [22] [23] [24].

Continuous viscous damping models are generally implemented removing the hypothesis of rigid block dynamics and describing the rocking behavior assuming a single degree of freedom (SDOF) system characterized by a one-dimensional bi-linear [25] or tri-linear [5] [26] force-displacement relationship, as depicted in Figure 2, where the backbone curve of the ideal rigid block equilibrium path is characterized by the ultimate load multiplier $\left(F_{0}\right)$ and the ultimate displacement $\left(\Delta_{u}\right)$ while the SDOF system is characterized by the initial elastic stiffness $\left(k_{L}\right)$, the yield force $\left(F_{y}=\beta F_{0}\right)$ and the yield displacement $\left(\Delta_{y}=\mathrm{F}_{y} / \mathrm{k}_{L}\right)$.

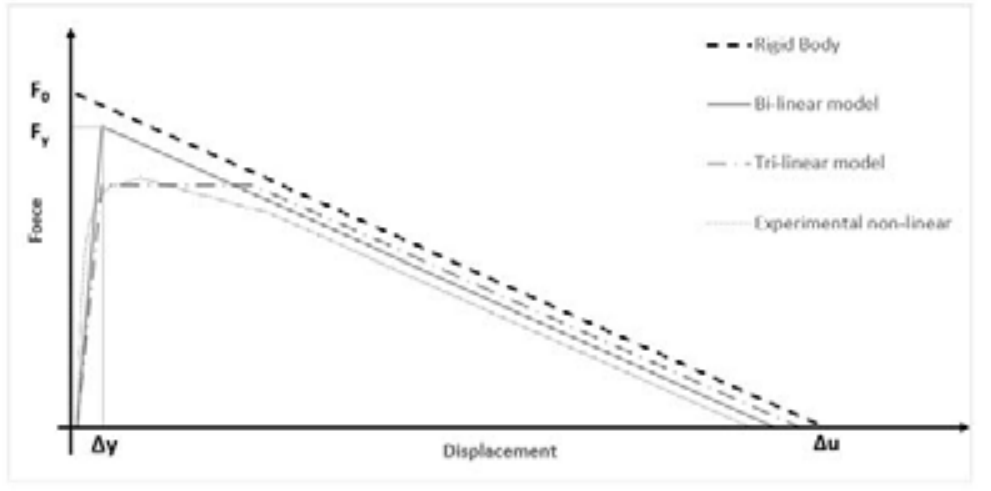

Figure 2: Force-displacement relationship models

Several studies have been performed to find a correlation relation between the equivalent viscous damping ratio, $\xi$, and the dissipation related to impacts controlled by coefficient of restitution [16] [20] [27] [28]. More recently, Tomasetti et Al. [21] proposed an energy equivalence between restitution coefficient and SDOF analytical formulation for different viscous damping models, constant damping coefficient (CDC), constant damping ratio (CDR) and stiffness-proportional damping ratio (SDR), proposing the empirical expression reported in Eq. (5) to evaluate the damping ratio $\xi_{e q}$ to associate to the initial elastic frequency of the system $\left(\omega_{L}=\sqrt{K_{L} / m_{e f f}}\right)$, where $m_{e f f}$ is the effective mass of associated to the system [21]. They found $\quad x_{C D C}=0.667, x_{C D R}=0.350, x_{S D R}=0.218$ and $\quad y_{C D C}=0.450, y_{C D R}=0.074$, $y_{S D R}=0.195$. 


$$
\xi_{e q}=-x\left(\Delta_{y} / \Delta_{u}\right)^{y} \ln (e)
$$

\subsection{The Discrete Macro-Element Model}

According to Discrete Macro-Element (DMEM) approach, the masonry is modelled through an equivalent mechanical scheme constituted by a hinged quadrilateral, whose in-plane deformability is governed by a single Lagrangian parameter, to rule the diagonal shear behavior. Each macro-element interacts with contiguous elements or constraints along its four edges by means of a discrete distribution of nonlinear springs, denoted as interfaces which govern the flexional and the sliding behavior. This approach was originally introduced for modelling the in-plane behavior of Unreinforced Masonry Structures [9], Figure 3a. The plane element possesses four degrees of freedom, a single row of transversal links and a single in-plane sliding link and is able to model the main failure mechanisms of the masonry in its own plane. Two subsequent upgrades were achieved to expand the potentialities of the approach. First, the out of plane (spatial) behavior, typical of historical constructions, was added [10] by considering additional rows of transversal links and two additional out-of-plane sliding links (able to govern the out of plane shear behavior and the torsion), thus enabling the out of plane degrees of freedom, Figure 3b. Subsequently, a further upgrade was introduced considering a shell macroelement characterized by an irregular geometry, variable thickness along the element and skew interfaces [29] to deal with curved structures, such as vaults and domes, Figure 3c.


(c)

Figure 3: Layout of the macro-element adopted for masonry at its three stages: (a) plane element, (b) spatial regular element and (c) three-dimensional element for curved structures.

The flexural (rocking) response of macro-elements is governed by the interface transversal links which are calibrated following a fibre-discretization approach of the panel cross section [10]. According to this strategy, the initial stiffness of the links is related to the axial stiffness of the corresponding masonry strips, evaluated in Eq. (8) where $E_{\mathrm{m}}$, is the masonry Young's modulus and $L_{\mathrm{n}}, A_{\mathrm{Sn}}$. the length and cross-section area of the masonry strip. The yielding forces in tension $\left(F_{\mathrm{ytn}}\right)$ and in compression $\left(F_{\mathrm{ycn}}\right)$ are related to the influence area and to the tensile and compressive strength respectively. Finally, the tensile and compressive yielding displacement $\left(u_{\mathrm{yt}}\right.$ and $u_{\mathrm{yc}}$ ) are associated with the yielding forces and the initial stiffness, Table 1.

The DMEM has been employed to simulate the seismic behavior of monumental masonry constructions by means of non-linear static (pushover) analysis. A more recent upgrade extended the DMEM approach to the dynamic field allowing the simulation of the non-linear dynamic behavior under seismic load. The mass of each macro-element is concentrated at its barycenter. According to this hypothesis, a diagonal mass matrix with, along the diagonal, the three translational inertia components and the three rotational inertia components of the volume represented by the macro-element [13]. More details on the DMEM are reported in the 
referenced papers.

\begin{tabular}{ccccc}
\hline$K_{n}$ & $F_{y t n}$ & $F_{y c n}$ & $u_{y t}$ & $u_{y c}$ \\
\hline $2 \frac{E_{m} A_{S n}}{L_{n}}$ & $A_{S n} \cdot f_{t n}$ & $A_{S n} \cdot f_{c n}$ & $\frac{F_{y t}}{K_{n}}$ & $\frac{F_{y c}}{K_{n}}$ \\
\hline
\end{tabular}

Table 1: Calibration of the interface transversal links.

\section{NUMERICAL SIMULATIONS}

The numerical simulations are performed considering rectangular blocks subjected to twoside rocking motion. Free vibration motion is considered in Section 3.1 whilst earthquake excitations are considered in Section 3.2.

Three models are considered. Namely, the ideal rigid block (RB) model, Figure 3a, a simplified DMEM model with the interfaces located at the base rocking section, Figure $2 b$, and a refined DMEM model in which the wall height is discretized by a mesh of macro-elements with height equal to the wall thickness, Figure $2 \mathrm{c}$. The response of the RB model is evaluated considering the analytical solution of Eq. (1) while, the analyses on the DMEM models are performed using the software HISTRA [30] through the Newmark method considering the Newmark's parameters $\alpha=0.9, \beta=0.25$ and $\gamma=0.5$ and a time step of $0.005 \mathrm{~s}$.

At each step, the dynamic equilibrium is imposed with reference to the initial configuration while the effects of the geometric nonlinearities are considered by updating the load vector position ( $P-\delta$ effects). The wall thickness is divided in ten rows of links and characterized by the distribution of normal stiffness $k_{n}=K_{n} / \lambda$ where $K_{n}$ already defined in Table 1 and $\lambda$ the distance between the links along the wall thickness. Although different constitutive laws can be adopted in the DMEM, aiming at performing a consistent comparison a linear behavior in compression and zero tensile strength have been assumed. Furthermore, a viscous damping, proportional to the global stiffness matrix, has been calibrated according to Eq. (6) evaluating the ratio $\Delta_{y} / \Delta_{u}$ through a pushover analysis.

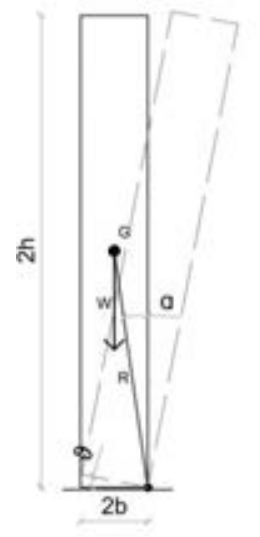

(a)

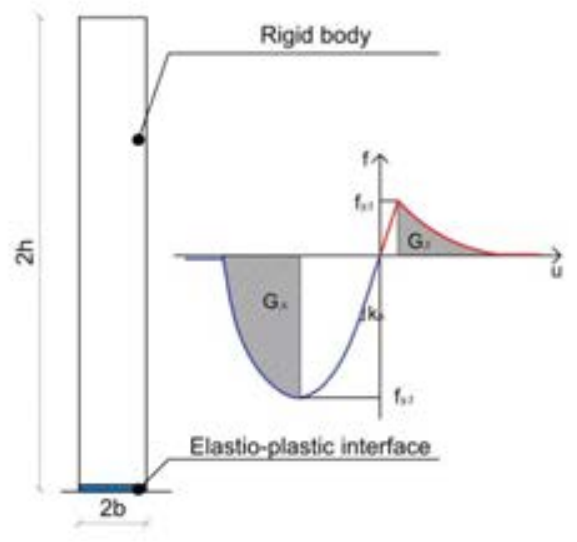

(b)



(c)

Figure 4: a) Rigid block model (RB), b) DMEM semplified model, c) DMEM refined model.

\subsection{Free-vibration analyses}

In this section, rectangular blocks subjected to two-side free-vibration rocking motions, activated imposing an initial displacement of the wall top section equal to the wall half-width $(b / 2)$, are analysed by the rigid block (RB), Figure 4a, and the DMEM model, Figure $4 \mathrm{~b}$ and 
Figure 4c. The analytical response of the RB is obtained by integrating Eq. (1) considering $\theta(0)=b / 4 ; \dot{\theta}(0)=0$. Two different parapet walls (PWs), characterized by different geometries and slenderness ratios $\left(\lambda_{\mathrm{w}}\right)$ and already numerically investigated in the literature [21], are considered.

For simplified DMEM models, two different values of coefficient of restitution are considered in the analyses, namely the analytical value $\left(e_{a n}\right)$ calculated by Eq. $(4)$ and a reduced value of $(e=0.85)$ consistent with experimental observations [31]. The normal stiffness of the DMEM interfaces $\left(k_{\mathrm{n}}\right)$ is evaluated by considering a reference value of masonry Young modulus $E_{\mathrm{m}}=800 \mathrm{MPa}$. The effective mass $\left(m_{e f f}\right)$ used to evaluate the lateral frequency $\left(\omega_{\mathrm{L}}\right)$ is assumed equal to $4 / 3 \mathrm{~m}$ in the case of the DMEM and equal to the mass activated at the first mode of vibration in the case of the DMEM refined model. The complete set of parameters characterising the DMEM simplified model is reported in Table 2 while, the characterisation of the DMEM refined model is reported in Table 3 where both the stiffness of the base interface $\left(k_{n, \text { base }}\right)$ and inner interfaces connecting two contiguous macro-elements $\left(k_{\mathrm{n}, \text { base }}\right)$ are reported.

The time history of the top section of $\mathrm{PW}_{1}$ and $\mathrm{PW}_{2}$, obtained by the DMEM simplified model, are reported in Figure 5 and Figure 6, respectively. The results are compared with those obtained by RB solution. A satisfactory agreement is observed between the two models, in all the cases investigated, although the DMEM model tends to underestimate the peaks when compared to the RB model.

\begin{tabular}{|c|c|c|c|c|c|c|c|c|c|c|}
\hline Wall & $\begin{array}{c}2 \mathrm{~h} \\
{[\mathrm{~m}]}\end{array}$ & $\begin{array}{c}2 \mathrm{~b} \\
{[\mathrm{~m}]}\end{array}$ & $\begin{array}{l}\lambda_{\mathrm{w}} \\
{[-]}\end{array}$ & $\begin{array}{l}e_{\text {an }} \\
{[-]}\end{array}$ & $\begin{array}{c}\mathrm{k}_{\mathrm{n}} \\
{\left[\mathrm{N} / \mathrm{m}^{3}\right]}\end{array}$ & $\begin{array}{c}\mathrm{K}_{\mathrm{L}} \\
{[\mathrm{N} / \mathrm{m}]}\end{array}$ & $\begin{array}{c}\omega_{\mathrm{L}} \\
{[1 / \mathrm{s}]}\end{array}$ & $\begin{array}{c}\Delta_{y} / \Delta_{u} \\
{[-]}\end{array}$ & $\begin{array}{c}\xi_{\mathrm{SDR}}\left(\mathrm{e}_{\text {an }}\right) \\
{[-]}\end{array}$ & $\begin{array}{c}\xi_{\mathrm{SDR}}(\mathrm{e}) \\
{[-]}\end{array}$ \\
\hline & & & & & $3.8 \mathrm{E}+08$ & $4.6 \mathrm{E}+06$ & 14.98 & 0.086 & 0.011 & 0.057 \\
\hline & 4.2 & 0.6 & & 0.91 & $9.5 \mathrm{E}+08$ & $1.1 \mathrm{E}+07$ & 23.69 & 0.034 & 0.013 & 0.068 \\
\hline PW2 & 3.0 & 0.3 & 0.100 & 0.98 & $\begin{array}{c}5.3 \mathrm{E}+08 \\
13.3 \mathrm{E}+08\end{array}$ & $\begin{array}{l}1.6 \mathrm{E}+06 \\
3.9 \mathrm{E}+06\end{array}$ & $\begin{array}{l}14.69 \\
23.22\end{array}$ & $\begin{array}{l}0.12 \\
0.05\end{array}$ & $\begin{array}{l}0.0048 \\
0.0058 \\
\end{array}$ & $\begin{array}{l}0.053 \\
0.063\end{array}$ \\
\hline
\end{tabular}

Table 2: Details of the walls analysed by the simplified DMEM model.

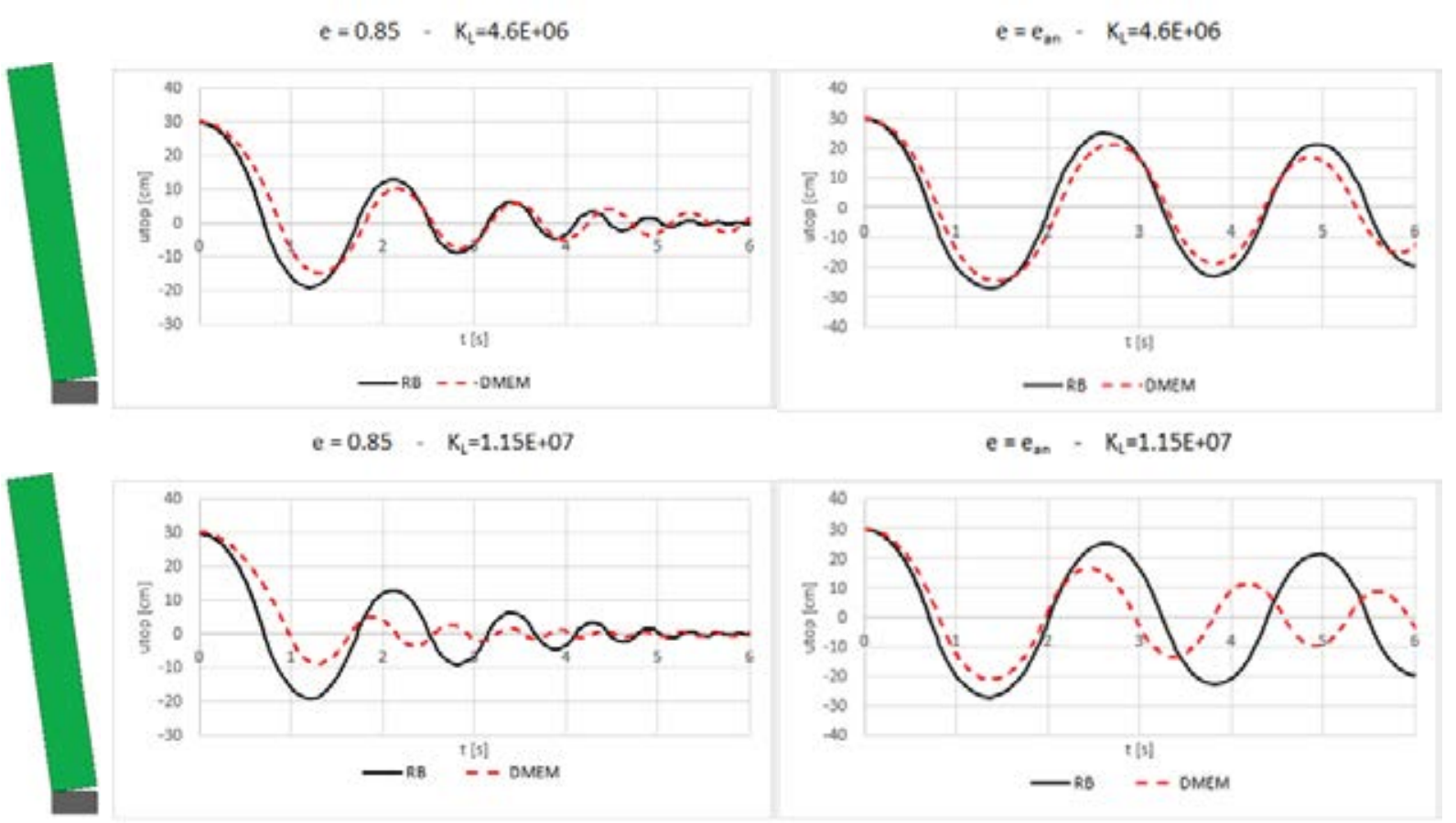

Figure 5: Free vibrations of the PW1 sample evaluated by the RB and simplified DMEM models. 


\begin{tabular}{ccccccccccc}
\hline Wall & $\begin{array}{c}2 \mathrm{~h} \\
{[\mathrm{~m}]}\end{array}$ & $\begin{array}{c}2 \mathrm{~b} \\
{[\mathrm{~m}]}\end{array}$ & $\begin{array}{c}\lambda_{\mathrm{w}} \\
{[-]}\end{array}$ & $\begin{array}{c}\mathrm{m}_{\text {eff }} \\
{\left[\mathrm{Ns}^{2} / \mathrm{m}\right]}\end{array}$ & $\begin{array}{c}\mathrm{k}_{\mathrm{n}, \text { base }} \\
{\left[\mathrm{N} / \mathrm{m}^{3}\right]}\end{array}$ & $\begin{array}{c}\mathrm{k}_{\mathrm{n}, \text { inner }} \\
{\left[\mathrm{N} / \mathrm{m}^{3}\right]}\end{array}$ & $\begin{array}{c}\mathrm{K}_{\mathrm{L}} \\
{[\mathrm{N} / \mathrm{m}]}\end{array}$ & $\begin{array}{c}\omega_{\mathrm{L}} \\
{[1 / \mathrm{s}]}\end{array}$ & $\begin{array}{c}\Delta_{y} / \Delta_{u} \\
{[-]}\end{array}$ & $\begin{array}{c}\xi_{\mathrm{SDR}}(\mathrm{e}) \\
{[-]}\end{array}$ \\
\hline PW1 & 4.2 & 0.6 & 0.143 & $\begin{array}{c}20550.5 \\
9850.5\end{array}$ & $5.3 \mathrm{E}+09$ & $2.7 \mathrm{E}+09$ & $1.2 \mathrm{E}+07$ & 24.24 & 0.049 & 0.063 \\
\hline PW2 & 3.0 & 0.3 & 0.100 & $\begin{array}{c}7339.45 \\
3398.2\end{array}$ & $1.1 \mathrm{E}+10$ & $5.3 \mathrm{E}+09$ & $3.7 \mathrm{E}+06$ & $\begin{array}{c}22.67 \\
33.32\end{array}$ & 0.063 & 0.060 \\
\hline
\end{tabular}

Table 3: Details of the walls analysed by the refined DMEM model.

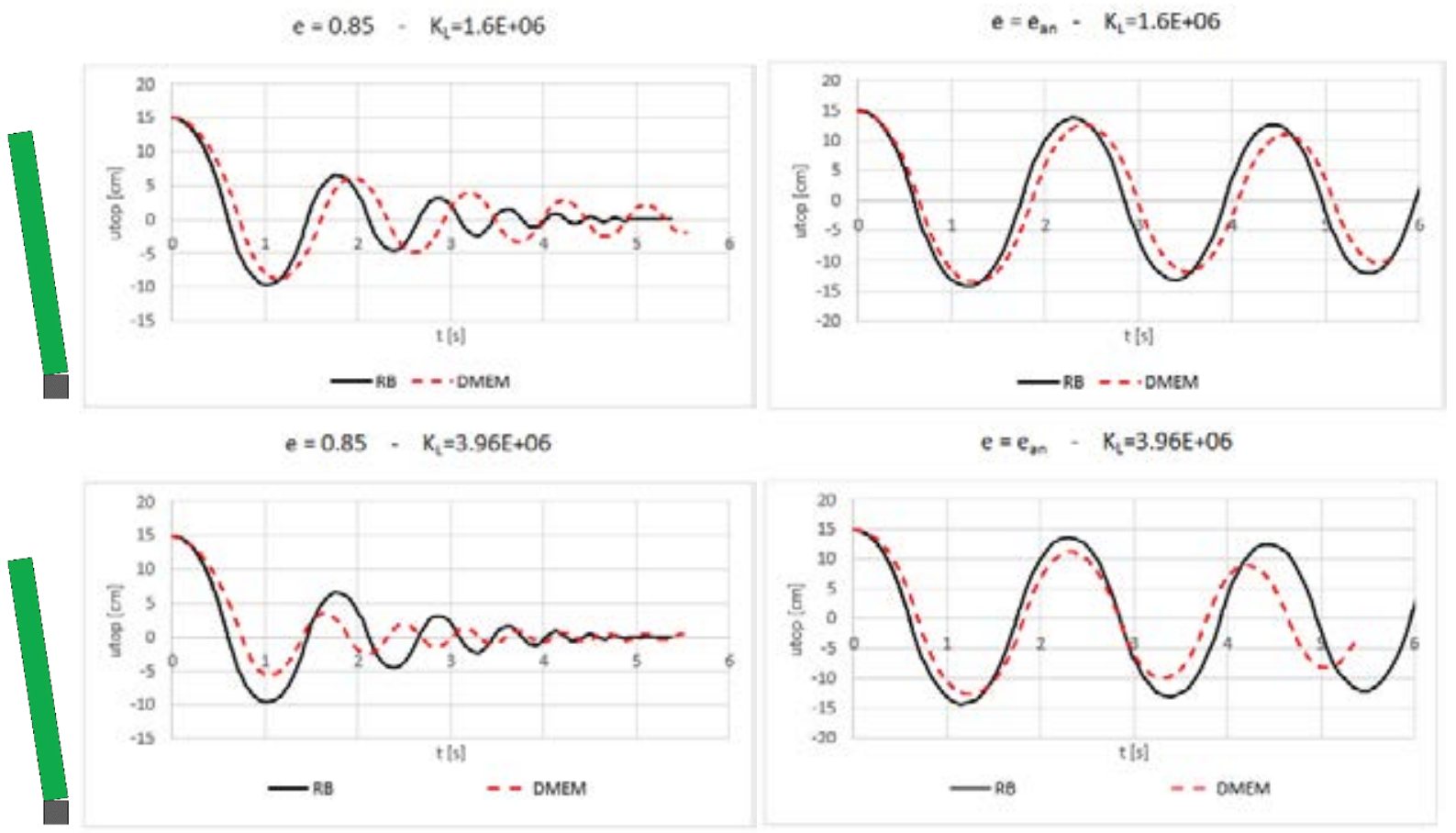

Figure 6: Free vibrations of the PW2 sample evaluated by the RB and simplified DMEM models.

The time history responses and the maximum deformation obtained by the DMEM refined model are reported in Figure 7 compared to the analytical solution of the rigid block model. The two models provide comparable results demonstrating that the equivalent viscous damping model adopted in the DMEM model is energetic consistent to the impact dissipation mechanism characterising the RB model. Finally, Figure 8 shows the hysteretic cycles of the DMEM models, expressed in terms of top displacement versus the wall base shear, superposed to the corresponding push-over curve. It can be observed that the dynamic responses show a significant deviation from the static curve due to the presence of the inertia and damping forces.
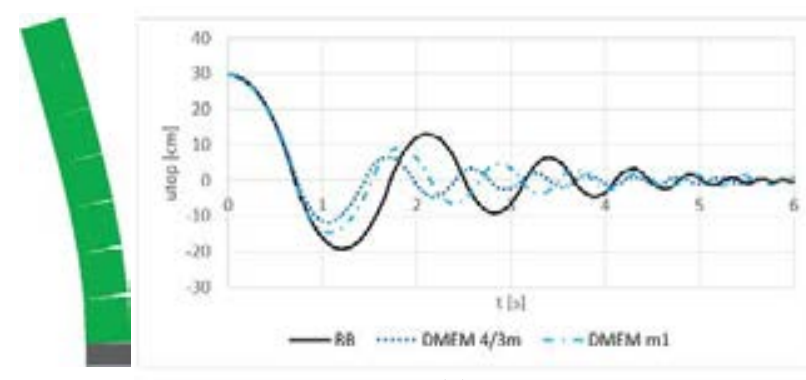

(a)

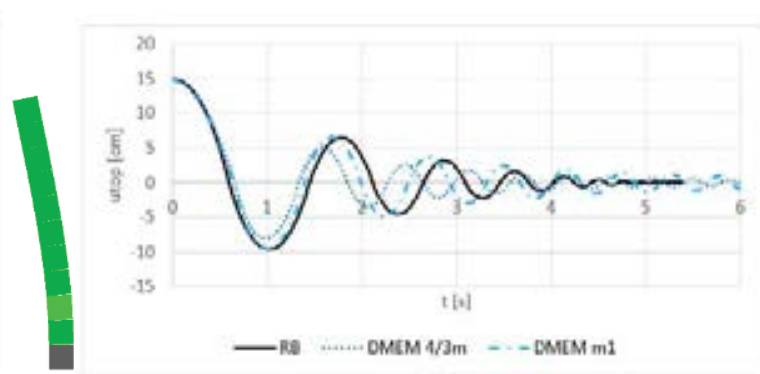

(b)

Figure 7: a) PW1 Refined DMEM, b) PW2 Refined DMEM. 


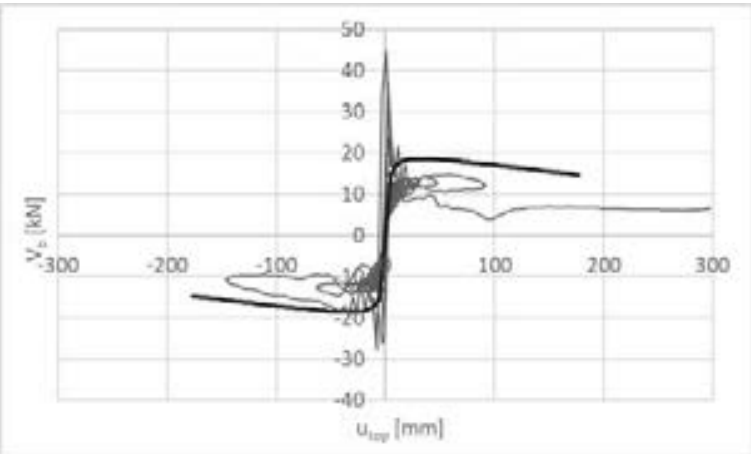

(a)

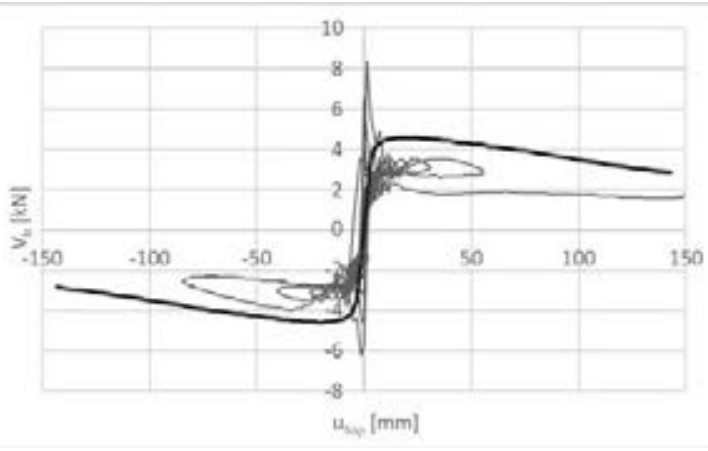

(b)

Figure 8: Pushover and dynamic hysteresis cycles a) PW1, b) PW2

\subsection{Earthquake analyses}

In this section, non-linear dynamic analysis under earthquake excitations are performed on a Vertical Spanning Walls (SPW) already experimentally and numerically investigated in the literature [32] [33]. The tested specimen was composed of regular tuff blocks, with self-weight $12.3 \mathrm{kN} / \mathrm{m}^{3}$, and lime-cementitious mortar. The wall was $3.48 \mathrm{~m}$ height, $1.53 \mathrm{~m}$ width and $0.25 \mathrm{~m}$ thick. On the top section of the wall it was located a reinforced brick-work beam $0.27 \mathrm{~m}$ height and $0.25 \mathrm{~m}$ thick, characterised by a self-weight of $18 \mathrm{kN} / \mathrm{m}^{3}$. The beam was connected to the underlying masonry with $600 \mathrm{~mm}$ long connectors in steel reinforced grout (SRG). The horizontal displacements of the beam were constrained by a steel IPE200 beams, placed on top of lateral stiffened steel frames. Rubber cylinders were placed between the IPE200 and the specimen to permit the upward displacement and rotations of the top section of the wall.

The test layout comprised an additional load of $6 \mathrm{kN}$ placed on the top of the reinforcedbrick beam. The characteristics of the input signals are reported in Table 4 . The specimen was numerical investigated by means of a 2D DEM model using the software UDEC (Itasca 2010) using different scale factors for the signals [32].

\begin{tabular}{ccccccccc}
\hline \multicolumn{2}{c}{ Earthquake information } & \multicolumn{4}{c}{ Horizontal component } & \multicolumn{3}{c}{ Vertical component } \\
\hline Event & $\begin{array}{c}\text { Record } \\
\text { station }\end{array}$ & Or. & $\begin{array}{c}\text { PGA } \\
{[\mathrm{g}]}\end{array}$ & $\begin{array}{c}\text { PGV } \\
{[\mathrm{mm} / \mathrm{s}]}\end{array}$ & $\begin{array}{c}\text { PGD } \\
{[\mathrm{mm}]}\end{array}$ & $\begin{array}{c}\text { PGA } \\
{[\mathrm{g}]}\end{array}$ & $\begin{array}{c}\text { PGV } \\
{[\mathrm{mm} / \mathrm{s}]}\end{array}$ & $\begin{array}{c}\text { PGD } \\
{[\mathrm{mm}]}\end{array}$ \\
\hline Irpinia 1980 & BGI & E-W & 0.18 & 344 & 117 & 0.10 & 154 & 74 \\
\hline
\end{tabular}

Table 4: Input signal

The DMEM model is developed using 78 macro-elements corresponding to 546 DoFs. The boundary conditions on the top of the wall are simulated by inserting elastic stiff macroelements whose mass density is evaluated to simulate the mass of the brick-wall beam plus the external load and restrained against the horizontal displacements. The analysis is performed in two stages, first a static analysis is conducted applying the gravity loads, then the dynamic analysis is performed assuming as initial condition the final configuration of the vertical analysis. The complete set of parameters characterising the DMEM models are reported in Table 5.

\begin{tabular}{|c|c|c|c|c|c|c|c|c|c|c|c|}
\hline $\begin{array}{c}\mathrm{h} \\
{[\mathrm{m}]}\end{array}$ & $\begin{array}{c}\mathrm{b} \\
{[\mathrm{m}]}\end{array}$ & $\begin{array}{l}\mathrm{e}_{\text {an }} \\
{[-]}\end{array}$ & $\begin{array}{c}\mathrm{k}_{\mathrm{n}} \\
{\left[\mathrm{N} / \mathrm{mm}^{3}\right]}\end{array}$ & $\begin{array}{c}\mathrm{K}_{\mathrm{L}} \\
{[\mathrm{N} / \mathrm{m}]}\end{array}$ & $\begin{array}{c}\mathrm{E} \\
{\left[\mathrm{N} / \mathrm{mm}^{2}\right]}\end{array}$ & $\begin{array}{c}\sigma_{\mathrm{t}} \\
{\left[\mathrm{N} / \mathrm{mm}^{2}\right]}\end{array}$ & $\begin{array}{c}\mathrm{G}_{\mathrm{t}} \\
{[\mathrm{N} / \mathrm{mm}]}\end{array}$ & $\begin{array}{c}\mathrm{m}_{\text {eff }} \\
{\left[\mathrm{Ns}^{2} / \mathrm{m}\right]}\end{array}$ & $\begin{array}{c}\omega_{\mathrm{L}} \\
{[1 / \mathrm{s}]}\end{array}$ & $\begin{array}{c}\Delta_{y} / \Delta_{u} \\
{[-]}\end{array}$ & $\begin{array}{c}\xi_{\mathrm{SDR}}(\mathrm{e}) \\
{[-]}\end{array}$ \\
\hline 3.48 & 1.53 & 0.85 & $4.9 \mathrm{E}+08$ & $1.05 \mathrm{E}+06$ & 294 & 0.001 & 0.01 & 1112.64 & 30.69 & 0.064 & 0.060 \\
\hline
\end{tabular}

Table 5: Parameters characterizing the DMEM model 
The results of the analyses are reported in Figure 9 in terms of time history of the point subject to maximum displacement which is located approximately at a height of $2.15 \mathrm{~m}$. The Different amplification factors are considered to scale the signal $(\mathrm{SF}=1.25 ; 1.5 ; 2.0)$. In Figure $9 \mathrm{a}$ the response of the wall to the signal scaled by 1.25 scale factor is shown. In the graph, the maximum displacement registered during the test are also reported. A very good agreement can be observed between the peak displacement predicted by the DMEM model and that observed experimentally. In Figure $9 \mathrm{~b}$ the numerical responses to the different levels of amplification of the signal are reported. It is evident how the DMEM model is able to catch the period elongation of the system due to the opening of the tensile cracks and the activation of the rocking mechanism.
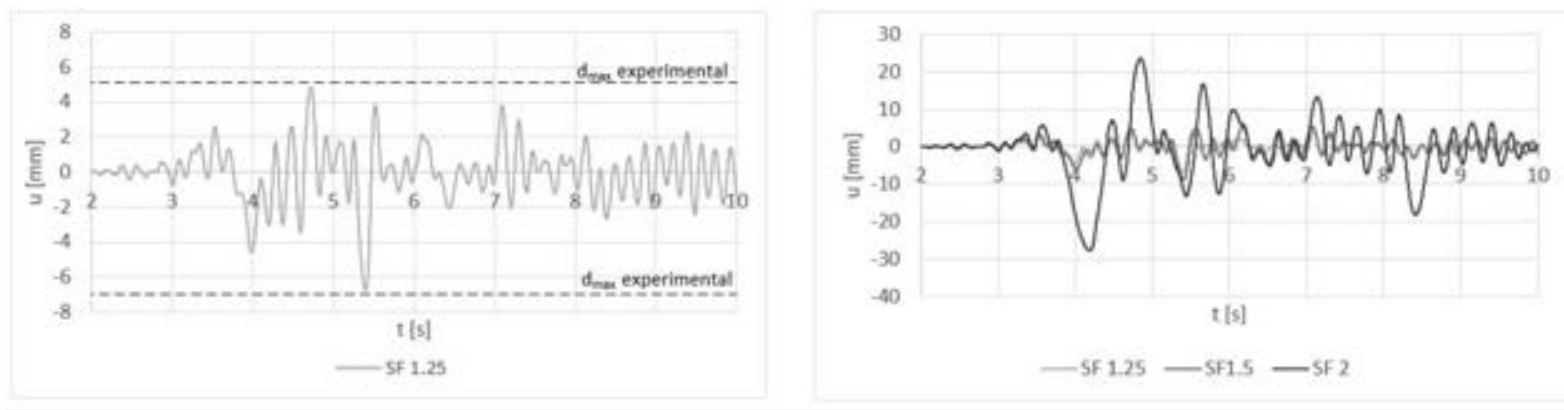

Figure 9: Time history DMEM model

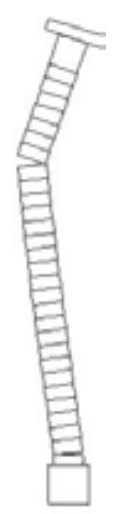

(a)

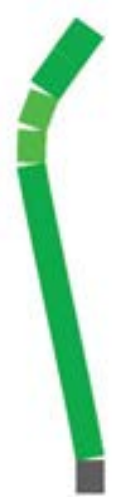

(b)

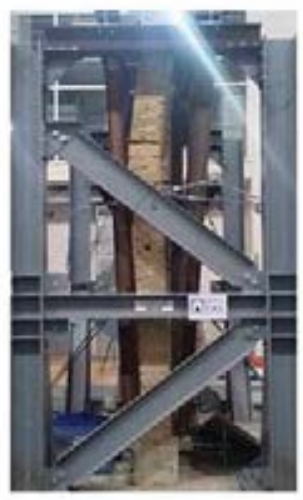

(c)

Figure 10: Failure mechanism estimated by; a) DEM model [32], b) DMEM model, c) experimental [32]

\section{CONCLUSIONS}

This paper applies the DMEM model to simulate the rocking behaviour of unreinforced masonry walls. The results of the DMEM model are compared with the exact solution consistent to the rigid block theory as well as to an experimental campaign for which other numerical strategies have already been applied. The effects of the energy dissipation and masonry deformability are investigated in the analysis. A stiffness-proportional viscous damping model to be employed in the DMEM analyses has been calibrated and validated. The results demonstrate that the DMEM can be adopted to accurately predict the dynamic response of monumental structures with a limited computational burden showing the capability of the method to be employed for the simulation of large historical masonry monumental structures, being able to simulate both the in-plane and out-of-plane response of masonry walls. 


\section{REFERENCES}

[1] M. Aslam, A. M. ASCE, W. G. Godden, M. ASCE and T. Scalise, Earthquake rocking response of rigid bodies, 1980.

[2] J. Heyman, "The stone Skeleton," International Journal of Solids and Structures, vol. 2(2), pp. 249-256, 1966.

[3] D. D. d. F. G. M. L. S. M. G. Sorrentino L., "Review of Out-of-Plane Seismic Assessment Techniques Applied To Existing Masonry Buildings," International Journal of Architectural Heritage, vol. 11, pp. 2-21, 2016.

[4] M. Andreini, A. De Falco, L. Giresini and M. Sassu, "Collapse of the historic city walls of Pistoia (Italy): causes and possible interventions.," Adv. in Civil Structures, no. 352, pp. 1389-1392.

[5] K. Doherty, M. C. Griffith, N. Lam and J. Wilson, "Displacement-based seismic analysis for out-of-plane bending of unreinforced masonry walls," Earthquake Engineering and Structural Dynamics, vol. 31, pp. 833-850, 2002.

[6] G. W. Housner, "The behavior of inverted pendulum structures during earthquakes," Bulletin of the Seismological Society of America, vol. 53, no. 2, pp. 403-401, 1963.

[7] T. M. Ferreira, A. A. Costa and A. Costa, "Analysis of the Out-of-Plane Seismic Behaviour of Unreinforced Masonry: A Literature Review," International Journal of Architectural Heritage, vol. 9, pp. 949-972, 2015.

[8] S. Caddemi, I. Caliò, F. Cannizzaro and B. Pantò, "New Frontiers on seismic Modeling of masonry Structures," Frontiers in Built Environment, pp. 3-39, 2017.

[9] I. Caliò, M. Marletta and B. Pantò, "A new discrete element model for the evaluation of the seismic behavior of unreinforced masonry buildings," Enginnering Structures, vol. 40, pp. 237-338, 2012.

[10] B. Pantò, F. Cannizzaro, I. Caliò and P. B. Lourenço, "Numerical and experimental validation of a 3D macro-model for the in-plane and the ouy-of-plane behavior of unreinforced masonry walls," International Journal of Architectural Heritage, 2017.

[11] C. Chàcara, P. B. Lourenço, B. Pantò, F. Cannizzaro and I. Caliò, "Parametric numerical studies on the dynamic response of unreinforced masonry structures," in Structural Analysis of Historical Constructions: Anamnesis, Diagnosis, Therapy, Controls, Leuven, Belgium, 2016, 13-15 Settembre.

[12] C. J. C. Espinoza, Macro-Element Nonlinear Dynamic Analysis for the Assessment of the Seismic Vulnerability of Masonry Structures, PhD Thesis, Universidade do Minho, Escola de Engenharia, 2018.

[13] C. Chàcara , F. Cannizzaro, B. Pantò, I. Caliò and P. B. Lourenço, "Assessment of the dynamic response of unreinforced masonry structures using a macro-element modelling approach," Earthquake Engineering and Structural Dynamics, vol. 47, pp. 2426-2446, 2018.

[14] F. Cannizzaro and P. B. Lourenço, "Simulation of shake table tests on out-of-plane masonry buildings," International Journal of Architectural Heritage, vol. 11(1), pp. 125142, 2017.

[15] A. N. Kounadis, "New findings in the rocking instability of one and two rigid block system under ground motion," Meccanica, vol. 50, pp. 2219-2238, 2015. 
[16] M. Priestley, R. Evison and A. Carr, "Seismic Response of Structures free to rock on theri foundation," Bullettin of New Zealand Society of Earthquake Engineering, vol. 11, pp. 141-150, 1978.

[17] A. K. C. J. P. C. Y. Yim, Rocking response over Rigid blocks to eearthquakes, Berkley, California: University of California, 1980.

[18] A. N. Kounadis, "Parametric studi in rockinf instability of a rigid block under harmonic ground pulse: A unified approach," Soil Dynamics and Earthquake Engineering, pp. 125$143,2013$.

[19] Y. Ishiama, "Motions of rigid bodies and criteria for overturning by earthquake excitations," in 3rd South Pacific Regional Conference on Earthquake Engineering, Wellington, 1983.

[20] N. Makris and D. Konstantinidis, "The rocking spectrum and the limitations of practical design methodologies," Earthquake Engineering and structural dynamics, vol. 32, pp. 265-289, 2003.

[21] U. Tomasetti, F. Graziotti, L. Sorrentino and A. Penna, "Modelling rocking response via equivalent viscous damping," Earthquake Engineering and Structural Dynamics, vol. 48, pp. 1277-1296, 2019.

[22] M. C. Griffith, G. Magenes, G. Melis and L. Picchi, "Evaluation of Out-of-Plane Stability of Unreiforced Masonry Walls Subjected to Seismic Excitation," Journal of Earthquake Engineering, vol. 7, pp. 141-169, 2003.

[23] N. Lam, M. Griffith, J. Wilson and K. Doherty, "Time-history analysis of URM walls in out-of-plane flexure," Eng Struct., vol. 25, no. 6, pp. 743-754, 2003.

[24] U. Tomasetti, F. Graziotti, A. Penna and G. Magenes, "Modelling one-way out-of-plane response of single-leaf and cavity walls," Eng Struct., vol. 167, pp. 241-255, 2018.

[25] S. Lagomarsino, "Seismic assessment of rocking masonry structures," Bull Earthquake Engineering, vol. 13, pp. 97-128, 2015.

[26] O. Al Shawa, G. de Felice, A. Mauro and L. Sorrentino, "Out-of-plane seismic behavior of rocking masonry walls," Earthquake Engineering and Structural dynamics, vol. 41, pp. 949-968, 2012.

[27] R. Giannini and R. Masiani, "Risposta in frequenza del blocco rigido: stabilità delle soluzioni," in Proceedings of the 10th Italian National Conference of Theoretical \& Applied Mechanisms, Pisa, Italy, 1990.

[28] M. J. DeJong and E. G. Dimitrakopoulos, "Dynamically equivalent rocking structures," Earthquake Engineering and Structural Dynamics, vol. 43, pp. 1543-1563, 2014.

[29] I. Caliò, F. Cannizzaro and M. Marletta, "A discrete element for modelling masonry vaults," Adv. Mater. Res., pp. 133-134;447-452, 2010.

[30] G. S. s.r.1., "HiStrA (Historical Structure Analysis)", Catania, Italy, 2015.

[31] A. A. Costa, A. Arede, A. Penna and A. Costa, "Experimental Evaluation of the coefficient of restitution of rocking stone masonry facades," in 15th International Brick and Block masonry conference, Florianopolis, Brasil, 2012.

[32] P. Meriggi, S. De Santis, G. de Felice and F. Gobbin, "Distinct Element Modelling of Masonry Walls under Out of Plane Seismic Loading," International Journal of Architextural Heritage, 2019. 
[33] D. C. G. d. G. F. D. F. E. R. I. De Santis S., "Seismic out-of-plane vertial bending behavior of masonry walls reinforced with textile reinforced mortar," in 10th International Masonry Conference, Milano, Italy, 2018.

[34] M. Tomazevic, The computer program POR, Ljubljana, Slovenia, 1978.

[35] T. M., Earthquake-Resistant Design of Masonry Buildings, 1st ed., vol. vol. 1, IMPERIAL COLLEGE PRESS, 1999.

[36] G. Magenes and G. S. Calvi, "In-plane seismic response of brick masonry walls," Earthquake Engineering and Structural Dynamics, vol. 26, pp. 1091-112, 1997.

[37] G. Magenes and A. Della Fontana, "Simplified non-linear seismic analysis of masonry buildings," 1998.

[38] S. Lagomarsino, A. Penna, A. Galasco and S. Cattari, "TREMURI program: An equivalent frame model for the nonlinear seismic analysis of masonry buildings," Engineering structure, vol. 56, pp. 1787-99, 2013.

[39] A. Tzmatzis and P. Asteris, "Finite Element analysis of masonry structures: Part I-Review of previous work," 2003.

[40] P. Roca, M. Cervera , G. Gariup and L. Pelà, "Structural analysis of masonry historical constructions. Classical and advanced approaches," Arch Comput Methods Eng, 2010.

[41] P. A. Cundall, "Formulation of a three dimensional distinct element model - Part I: A scheme to detect and represent contacts in a system composed of many polyhedral blocks," International Journal of Rock Mechanism and Mining Sciences, vol. 25, pp. 107$116,1988$.

[42] J. V. Lemos, "Discrete Element Modelling of Maonry Structures," International Journal of Architectural Heritage, vol. 1, pp. 190-213, 2007.

[43] C. Casapulla, L. Giresini, M. Sassu and P. B. Lourenço, "Rocking and kinematics approaches fo masonry walls: state of art and recent developments," Buildings, 2017.

[44] R. D. Hart, P. A. Cundall and J. V. Lemos, "Formulation of a three-dimensional distinct element model - Part II: Mechaniccal calculations," International Journal of Rock Mechanism and Mining Sciences, vol. 25, pp. 117-125, 1988.

[45] C.-S. Yim, A. K. Chopra and J. Penzien, "Rocking response of rigid blocks to earthquakes," National echnical information service, Berkeley, California, 1980.

[46] M. Giaretton, J. Ingham and D. Dizhur, "Dynamic testing of as-built clay brick unreinforced masonry parapets," Engineering Structures, vol. 127, pp. 676-685, 2016. 